\title{
Open Source System for Smart Home Devices Based on Smartphone Virtual Assistant
}

\author{
Dwi Susanto ${ }^{1}$, Faaris Mujaahid ${ }^{* 1}$, Ramadoni Syahputra ${ }^{1}$, Karisma Trinanda Putra ${ }^{1,2}$ \\ ${ }^{1}$ Department of Electrical Engineering, Faculty of Engineering, Universitas Muhammadiyah Yogyakarta \\ Bantul 55183 Daerah Istimewa Yogyakarta, Indonesia \\ ${ }^{2}$ College of Information and Electrical Engineering, Asia Uniersity \\ Liufeng Road 500, Wufeng District, Taichung City, Taiwan 41354 \\ *Corresponding author, e-mail: f.mujaahid@umy.ac.id
}

\begin{abstract}
No doubt, the functionality of smartphones and the internet is now very diverse. Various features and applications in it are present to simplify human life, including the voice assistant feature. This study raises the theme of utilizing voice assistant for the purposes of controlling smart household devices based on the IoT module. The IoT NodeMCU module has an integrated WiFi chip, works with low power settings and supports flexible programming languages using the Arduino IDE. Testing using Android OS 5.0.2 version and 7.1.2 version generate four different results, which are $100 \% \& 83.33 \%$ accuracy for male voices and $83.33 \% \& 58.33 \%$ when tested using female voices. The accuracy is determined by several reasons i.e. system version, the quality of the microphone, noise, and voice articulation when giving commands to the Google Assistant.
\end{abstract}

Keywords: IoT, NodeMCU, Arduino, Android, Google Assistant

\section{Introduction}

Internet of Things (IoT) is a network concept that enables the physical devices, i.e home appliances, communication gadgets, and other items equipped with electronics, software, and connectivity, to interconnect and to interchange data among each other on the existing internet infrastructure [1]. The discussion over IoT has become significantly a popular topic both in the academic forum and public society. Due to its association with the internet where the data is quickly and globally spread, IoT system can enhance our activities and daily lives. Not to mention that this technology has a very promising future to be applied in every human business, from the small-scale household appliances to the large-scale industries e.g. smart city, smart grids, and agriculture.

Apart from the IoT, nowadays the smartphone has impacted the way people socialize and transformed the communication culture of modern society [2]. Unless the smartphone is used wisely, people tend to spend their time more with their gadgets instead of socializing and gathering with their relatives or friends. However, smartphone can be utilized sensibly to increase our productivity and effectively perform some tasks. One example on utilizing the smartphone is by integrating the gadget with the IoT, i.e. monitoring the energy use, connecting with the CCTV, or controlling the home appliances remotely.

Voice assistant or intelligent personal assistants is one the smartphone feature that can support the IoT development [3]. This feature enables the user to have two-ways communication with the smartphone through voice commands. By using this feature, the user may have an alternative method to communicate with the smartphone. The big companies, i.e. Google, Amazon, Apple, and Microsoft, have developed their voice assistant respectively are Google Assistant, Alexa, Siri, and Cortana. Combining the smartphone voice assistants and the IoT, it will produce a wide range application in the sector of smart homes and buildings [4]. 
The purpose of this work is to develop the prototype of an open source IoT system that can perform a simple task for smart home devices. The control is executed remotely over a Wi-Fi network from a voice virtual assistant provided by Google. Technically, the idea is to turn on and off the two lights. Both lights are connected to the controllable relay and built in Wi-Fi single-board. With the help of virtual assistant on smartphone, the user can give commands remotely to the relay to switch on and off the two lights.

This paper mainly focuses on the hardware system. The components used to build the prototype are NodeMCU microcontroller, 2-channel relay module board, two light bulbs, and power supply. The explanation about the software is also included briefly to complete the overall description of the system.

\section{Related Work}

The use of IoT has been demonstrated widely on any sectors. A. Djajadi and M. Wijanarko in 2016 reported their work about the sensor network to monitor the ambient environment quality. The methodology used was to measure the intensity of the selected parameters on the air. Those parameters are carbon monoxide, carbon dioxide, liquid petroleum gas (LPG), alcohol, illuminance, air temperature, air humidity, and sound. The results of the sensors measurement are sent to the web-server for online monitoring purpose [5]. Another use of IoT for the environmental is to monitor the $\mathrm{pH}$ value of the water to maintain the water quality [6]. Several components are used to build the system, i.e. $\mathrm{pH}$ sensor, microcontroller, $\mathrm{RF}$ modem, and servers.

The term of intelligent personal assistant (IPA) is interchangeable with digital personal assistant (DPA). Voice assistant is part of IPA/DPA that recognizes user's command in natural language to execute more diverse and different tasks [7]. In 2018, Azat Khusnutdinov et al developed an Open Source DPA that can transform the user's utterances into machine commands to control the smart home automation module [7].

A team from Sree Buddha College of Engineering has developed a smart robotic assistant that is remotely operated by an Android smartphone [8]. The user gives a voice or gesture instructions to the smartphone, then it will be converted to text commands and carried out on the Wi Fi network. Arduino board will receive the data and process them to control the robotic assistant.

\section{Proposed Method}

This section is divided into two sub-section; Hardware and Software. A brief description of the software system is firstly given to support the explanation of the overall system. Afterwards, the hardware system as the focus of this paper is described further.

A complete diagram of the system is depicted in Figure 1. It begins from the user Android-platform smartphone.

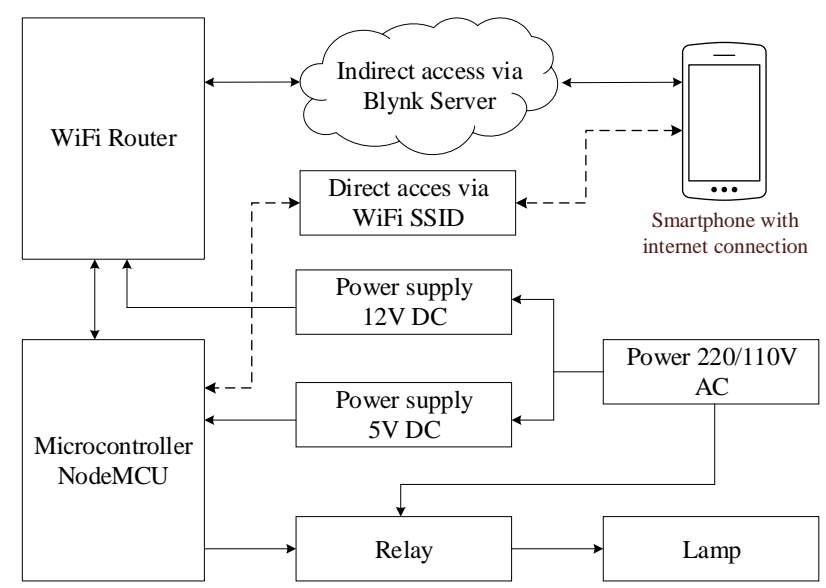

Fig. 1. Design of smart home device using IoT module NodeMCU

User can control the system in two ways. First, by using the Google Assistant application with voice commands to turn off and turn on the lights in real time. This method can be done directly without using an internet connection. Users can connect to the system via SSID emitted by the NodeMCU server. The second way is by using the Blynk application to turn off and turn on lights in real time, and even use scheduling.

When the system is turned on, the WiFi on the microcontroller is in "station" mode, then the system will try to connect to the last WiFi access point connected to the system, if the connection is successful then the microcontroller will be connected to the Blynk Cloud server, and the system is ready to use (online). Whereas, if the connection fails, WiFi on the microcontroller changes to "access point" mode with the name SSID "SmartRelay" and password "password123". In this mode the user connects his smartphone or PC/laptop with the WiFi. After the system device successfully connects to WiFi, the system will open a configuration portal through a browser. On this portal, the user selects $\mathrm{WiFi}$ access points that will 
be connected to the system. If the connection is successful then the microcontroller will be connected to the Blynk Cloud server, and the system is ready to use.

\section{A.Hardware}

As the main controller, NodeMCU microcontroller is used with ESP8266 chip which supports WiFi connection. This microcontroller is connected to a 5V 2-Channel Relay Module that will control two lights. Microcontroller and relay are both using the $5 \mathrm{~V}$ power supply from the $5 \mathrm{~V} 1 \mathrm{~A}$ Power Supply Board. I / O pins that are used as output on the microcontroller are GPIO14 (D5) and GPIO12 (D6). These pins are connected to the IN1 pin and IN2 pin of the relay. Vin microcontroller pin and VCC relay pin are connected to $+\mathrm{V}$ on the $5 \mathrm{~V}$ power supply, GND pin on the microcontroller is connected to $-\mathrm{V}$ on the power supply. The GND relay pin is connected to the GND $3.3 \mathrm{~V}$ microcontroller pin. In the high voltage relay terminal, using normally open (NO), so when the relay gets a high signal from the microcontroller, the light will turn on, and vice versa.

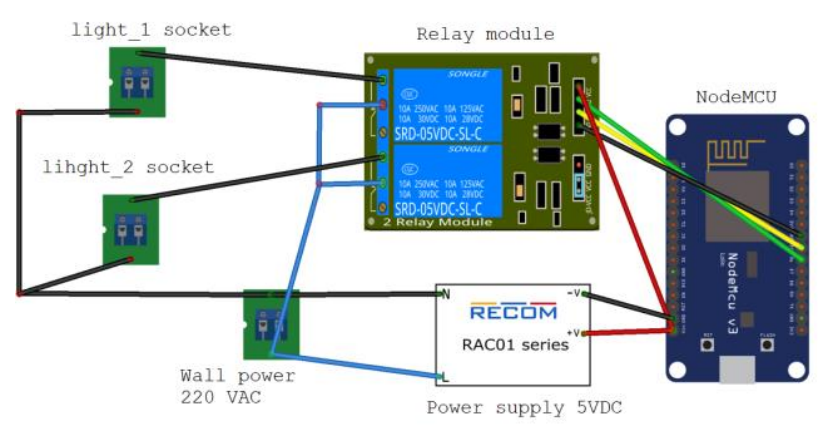

Fig. 2. Hardware design of smart home device

\section{B.Software}

This design is divided into the design of microcontroller software and the design of supporting applications software. Applications used in this study such as Blynk, IFTTT and Google Assistant. In addition, the microcontroller is programmed using the Arduino base to connect to the cloud server. The process of working on the software side of the final project will be outlined in the points below:

\section{1) Blynk}

The Blynk application can be downloaded free from Google Play on Android or the App Store on iOS. Then we create a new account and project on the Blynk application, after that the "auth token" will be emailed to us, later this "auth token" is used as verification so that our devices can connect to the "blynk cloud" server. On the Project page, the Blynk application provides many widget options that we can use in future projects.

\section{2) IFTTT}

The IFTTT application service on this system is used to "connect" Google Assistant and the microcontroller connected to the Blynk Cloud server. When a "certain" voice command is spoken to Google Assistant, the IFTTT service will send a web-request to the control system to update the pin value on the microcontroller, which will turn on or turn off the lights.

\section{3) Programming the Microcontroller with Arduino IDE}

The NodeMCU microcontroller is made with firmware that uses the Lua scripting language, but here, we prefer to use the Arduino IDE because the Arduino platform is more widely used and has more support from the related community. In the IFTTT application service, we can make a simple conditional statement chain called an Applet.

\section{Results}

Testing includes two parts, i.e. hardware testing and software testing. In hardware testing, the relay used is a 2-channel relay. This relay is active low, so when the input voltage is low, relay will be active, and vice versa. In microcontroller side, pin D5 and pin D6 are used as outputs that are connected to the relay. The pins on this microcontroller use a $3.3 \mathrm{~V}$ voltage. The measurement is done by metering the voltage pins D5 and pin D6 each with Ground pin when the relay is OFF and $\mathrm{ON}$.

This system can enable users to turn on and turn off the lights connected to the relay via voice commands with the Google Assistant application on the smartphone. Voice commands use English, because for now Google Assistant does not yet support Indonesian. The list of commands used is shown in Table 2.

The test is conducted in a closed room with a low noise level, aiming that the sound input obtained in the experiment can be maximized. Each voice command on Google Assistant is done twice. The first experiment was carried out with a Letv One Pro smartphone with a male voice tester. Then with the same smartphone, testing is done using a female voice. Next, this test will be repeated, but by using 
a different smartphone, namely Motorola Moto X. This test is carried out to see differences in smartphone hardware used, the quality of the microphone and different versions of the Android system.

From the test results in table 2-5, it can be seen that there are still errors that occur when giving voice commands to the Google Assistant application. The specification factor on the smartphone and the voice command provider turns out to have an effect on the percentage of errors that occur. Smartphones with the latest Android operating system are more accurate in processing voice commands than smartphones with the old operating system. Meanwhile, in terms of the voice command provider, testers with articulation when pronouncing voice commands in good English, are more accurate than testers with unclear articulation.

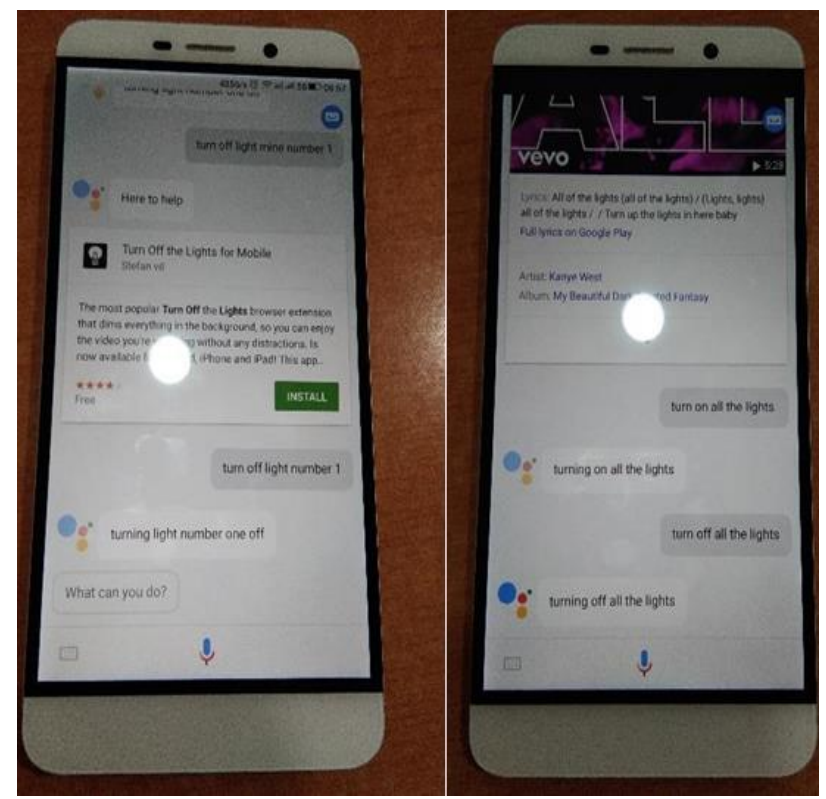

Fig. 3. Voice command testing using smartphone LeTV One Pro

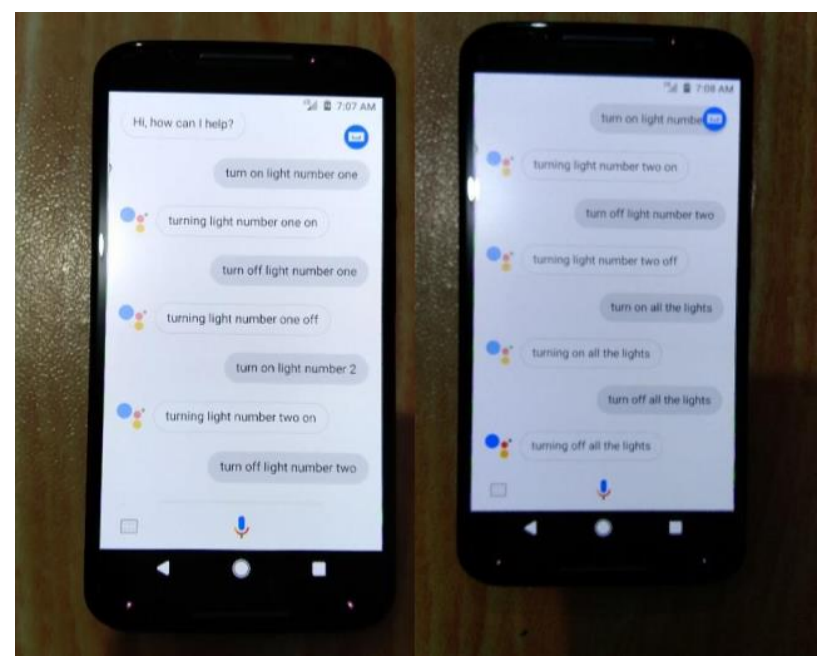

Fig. 4. Voice command testing using smartphone Moto X

TABLE I

Measuring OUtPut Voltage In Microcontroller

\begin{tabular}{ccccc}
\hline \hline No. & Relay 1 & Relay 2 & Pin D5 (V) & Pin D6 (V) \\
\hline 1 & OFF & OFF & $(3.27)$ & $(3.28)$ \\
2 & ON & OFF & $(0.05)$ & $(3.27)$ \\
3 & OFF & ON & $(3.27)$ & $(0.04)$ \\
4 & ON & ON & $(0.04)$ & $(0.04)$ \\
\hline \hline
\end{tabular}


TABLE II

Voice Command Test with MAN's Voice ANd SMARTPHone LeTV One Pro (ANDRoid 5.0.2)

\begin{tabular}{clcc}
\hline \hline & \multirow{2}{*}{$\begin{array}{c}\text { Google Assistane } \\
\text { Response }\end{array}$} & \multicolumn{2}{c}{$\begin{array}{c}\text { Expected \& Actual } \\
\text { Condition }\end{array}$} \\
\cline { 3 - 4 } & & Lamp 1 & Lamp 2 \\
\hline "turn on light number one" & "light number one on" & ON-ON & X-X \\
"turn on light number one" & "flight number one" & ON-OFF & X-X \\
"turn on light number two" & "light number two on" & X-X & ON-ON \\
"turn on light number two" & "light number two on" & X-X & ON-ON \\
"turn off light number one" & "light number one off" & OFF-OFF & X-X \\
"turn off light number one" & "light number one off" & OFF-OFF & X-X \\
"turn off light number two" & "flight number two" & X-X & OFF-ON \\
"turn off light number two" & "light number two off" & X-X & OFF-OFF \\
"turn on all the lights" & "all the lights on" & ON-ON & ON-ON \\
"turn on all the lights" & "all the lights on" & ON-ON & ON-ON \\
"turn off all the lights" & "all the lights off" & OFF-OFF & OFF-OFF \\
"turn off all the lights" & "all the lights off" & OFF-OFF & OFF-OFF \\
\hline \hline
\end{tabular}

TABLE III

Voice COMmand Test with Woman’s Voice ANd SMARTPHone LeTV One Pro (ANDroid 5.0.2)

\begin{tabular}{llcc}
\hline \hline User's Voice Command & \multicolumn{1}{c}{$\begin{array}{c}\text { Google Assistane } \\
\text { Response }\end{array}$} & \multicolumn{2}{c}{$\begin{array}{c}\text { Expected \& Actual } \\
\text { Condition }\end{array}$} \\
\cline { 3 - 4 } & & Lamp 1 & Lamp 2 \\
\hline "turn on light number one" & "number one" & $\underline{\text { ON-OFF }}$ & X-X \\
"turn on light number one" & "light number one on" & ON-ON & X-X \\
"turn on light number two" & "light number two on" & X-X & ON-ON \\
"turn on light number two" & "turn light number too" & X-X & ON-OFF \\
"turn off light number one" & "light number one off" & OFF-OFF & X-X \\
"turn off light number one" & "light number one off" & OFF-OFF & X-X \\
"turn off light number two" & "flight number two" & X-X & OFF-ON \\
"turn off light number two" & "light number two off" & X-X & OFF-OFF \\
"turn on all the lights" & "turn wall like" & ON-ON & OFF-OFF \\
"turn on all the lights" & "all the lights on" & ON-ON & ON-ON \\
"turn off all the lights" & "all the lights off" & OFF-OFF & OFF-OFF \\
"turn off all the lights" & "off wall lite" & OFF-OFF & ON-ON \\
\hline *X means do not care & & &
\end{tabular}

*X means do not care

TABLE IV

Voice Command Test with Man's Voice and Smartphone Moto X (Android 7.1.2)

\begin{tabular}{clcc}
\hline User's Voice Command & \multicolumn{2}{c}{$\begin{array}{c}\text { Google Assistane } \\
\text { Response }\end{array}$} & \multicolumn{2}{c}{$\begin{array}{c}\text { Expected \& Actual } \\
\text { Condition }\end{array}$} \\
\cline { 3 - 4 } & & Lamp 1 & Lamp 2 \\
\hline "turn on light number one" & "light number one on" & ON-ON & X-X \\
"turn on light number one" & "light number one on" & ON-ON & X-X \\
"turn on light number two" & "light number two on" & X-X & ON-ON \\
"turn on light number two" & "light number two on" & X-X & ON-ON \\
"turn off light number one" & "light number one off" & OFF-OFF & X-X \\
"turn off light number one" & "light number one off" & OFF-OFF & X-X \\
"turn off light number two" & "light number two off" & X-X & OFF-OFF \\
"turn off light number two" & "light number two off" & X-X & OFF-OFF \\
"turn on all the lights" & "all the lights on" & ON-ON & ON-ON \\
"turn on all the lights" & "all the lights on" & ON-ON & ON-ON \\
"turn off all the lights" & "all the lights off" & OFF-OFF & OFF-OFF \\
"turn off all the lights" & "all the lights off" & OFF-OFF & OFF-OFF \\
\hline \hline
\end{tabular}

*X means do not care 
TABLE V

Voice Command Test with Woman's Voice and SMartphone Moto X (ANDroid 7.1.2)

\begin{tabular}{|c|c|c|c|}
\hline \multirow[t]{2}{*}{ User's Voice Command } & \multirow{2}{*}{$\begin{array}{l}\text { Google Assistane } \\
\text { Response }\end{array}$} & \multicolumn{2}{|c|}{$\begin{array}{l}\text { Expected \& Actual } \\
\text { Condition }\end{array}$} \\
\hline & & Lamp 1 & Lamp 2 \\
\hline "turn on light number one" & "light number one on" & $\mathrm{ON}-\mathrm{ON}$ & $\mathrm{X}-\mathrm{X}$ \\
\hline "turn on light number one" & "turn flight number" & ON-OFF & $\mathrm{X}-\mathrm{X}$ \\
\hline "turn on light number two" & "light number two on" & $\mathrm{X}-\mathrm{X}$ & ON-ON \\
\hline "turn on light number two" & "light number two on" & $\mathrm{X}-\mathrm{X}$ & ON-ON \\
\hline "turn off light number one" & "light number one off" & OFF-OFF & $\mathrm{X}-\mathrm{X}$ \\
\hline "turn off light number one" & "light number one off" & OFF-OFF & $X-X$ \\
\hline "turn off light number two" & "term off like too" & $\mathrm{X}-\mathrm{X}$ & OFF-ON \\
\hline "turn off light number two" & "light number two off" & $\mathrm{X}-\mathrm{X}$ & OFF-OFF \\
\hline "turn on all the lights" & "all the lights on" & ON-ON & ON-ON \\
\hline "turn on all the lights" & "all the lights on" & ON-ON & ON-ON \\
\hline "turn off all the lights" & "all the lights off" & OFF-OFF & OFF-OFF \\
\hline "turn off all the lights" & "all the lights off" & OFF-OFF & OFF-OFF \\
\hline
\end{tabular}

*X means do not care

TABLE VI

RESULT'S SUMMARY AND SUCCESS RATE FROM TABLE 2-5

\begin{tabular}{ccc}
\hline \hline User & LeTV One Pro & Moto X \\
\hline Man, 34 years old & $83.33 \%$ & $100 \%$ \\
Woman, 27 years old & $58.33 \%$ & $83.33 \%$ \\
\hline \hline
\end{tabular}

\section{Conclusion}

In general, the prototype can work well, the user can control the relay to turn on and turn off the lights with voice commands through the Google Assistant application on the smartphone. The wifi manager feature on the device works well, so it can be used with WIFI devices that have different SSID and Password. From the male voice test using a Letv One Pro smartphone, the percentage of success was $83.33 \%$, while with female voice testers, the percentage of success was $58.33 \%$. On the other hand, on testing with the Motorola Moto $\mathrm{X}$ smartphone with male voice testers the percentage of success was $100 \%$, with female voice testers the percentage of success was $83.33 \%$. The success factor in the above experiment is determined by the software specifications on the smartphone, the quality of the microphone, background noise, and mainly due to the user's English articulation when giving voice commands to the Google Assistant application.

\section{References}

[1] Arduino. 2017. "What is Arduino?",

https://www.arduino.cc/en/guide/introduction,
[2] Ashton, K. 2009. That "Internet of Things" Thing. http://www.rfidjournal.com/articles/view?4986.

[3] Blynk Inc. 2017. Getting Started with Blynk. https://www.blynk.cc/getting-started, diakses Desember 2017.

[4] Escobar, Eric. 2013. "What Is IFTTT and How Can it Improve Your Digital Life?".

[5] https://www.quickanddirtytips.com/tech/web/whatis-ifttt-and-how-can-itimprove-your-digital-life.

[6] https://www.espressif.com/en/products/hardware/esp 8266ex/overview.

[7] G.Kulkarni, Udayakumar. 2017. Arduino: A Begineer's Guide. Google Books.

[8] Google. 2018. Create commands to control online services \& devices.

[9] Kurniawan, Agus. 2015. NodeMCU Development Workshop. PE Press. Depok.

[10] Kurniawan, Agus. 2015. SparkFun ESP8266 Thing Development Workshop. PE Press. Depok.

[11] Lynley, Matthew. 2016. Google unveils Google Assistant, a virtual assistant that's a big upgrade to Google Now. https://techcrunch.com/2016/05/18/googleunveilsgoogle-assistant-a-big-upgrade-to-google-now.

[12] Tibbets, Linden. 2014. ifttt the beginning. https://ifttt.com/blog/2010/12/ifttt-thebeginning. 


\section{Authors' information}

Dwi Susanto was a bachelor student of Electrical Engineering, Faculty of Engineering, Universitas Muhammadiyah Yogyakarta. He graduated in 2018.

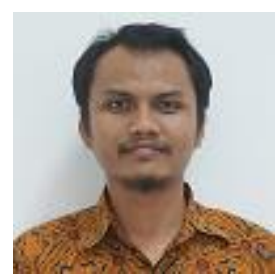

Faaris Mujaahid Hold a bachelor degree in 2010 from Electrical and Electronics Engineering Department, Saxion University of Applied Sciences, the Netherlands. He received a master degree in Sustainable Energy Technologies in 2016 from University of Southampton, UK. ing. Faaris Mujaahid, M.Sc. is currently a lecturer in the Department of Electrical Engineering, Faculty of Engineering, Universitas Muhammadiyah Yogyakarta, Indonesia. His main research interest is in LabVIEW and renewable energy (mainly in solar cell material and fabrication technologies).

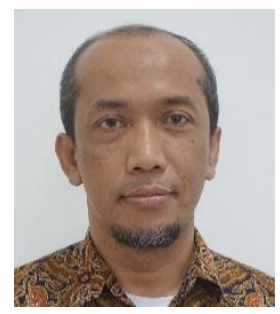

Ramadoni Syahputra received B.Sc. degree from Institut Teknologi Medan in 1998, M.Eng. degree from Department of Electrical Engineering, Universitas Gadjah Mada, Yogyakarta, Indonesia in 2002, and Ph.D degree at the Department of Electrical Engineering, Faculty of Industrial Technology, Institut Teknologi Sepuluh Nopember, Surabaya, Indonesia in 2015. Dr. Ramadoni Syahputra is a Lecturer in Department of Electrical Engineering, Faculty of Engineering, Universitas Muhammadiyah Yogyakarta, Indonesia. His research interests are in computational of power system, artificial intelligence in power system, power system control, the application of fuzzy logic in power system, optimization, distributed energy resources, and renewable energy.

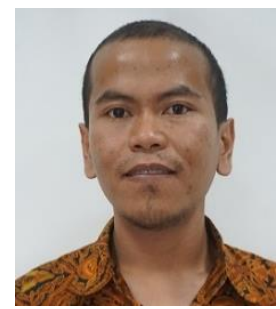

Karisma Trinanda Putra born in Bondowoso on June 19, 1990. Graduated from elementary to senior high school in Bondowoso until 2008. Studied bachelor degree program in Surabaya, precisely in Electronics Engineering Polytechnic Institute of Surabaya (EEPIS) until 2012. He got scholarship program to continue master degree in Institut Teknologi Sepuluh Nopember (ITS) Surabaya. Karisma is also a lecturer at Electrical Engineering, Faculty of Engineering, Universitas Muhammadiyah Yogyakarta. The main focus of research is the intelligent systems and controls. He engaged in joint research related to the development of food commodity tracking systems and integrated intelligent systems. He was involved in several competitions in developing smart devices. Pursue the field of electronics and software development since college. Mr. Putra joined in Indonesian's engineer union organization (PII) in 2016. Mr. Putra is also active in writing publications on IEEE society. 